\title{
"Usos e (ab)usos" do conceito de reestruturação: adjetivações e sentidos na compreensão da produção do espaço
}

"Uses et abuses » du concept de restructuration : qualifications et significations de la production de l'espace

"Uses and abuses" of the concept of restructuring: adjectival uses are felt in the understanding of the production of the space

Usos e abusos del concepto de reestructuración: adjetivaciones y sentidos en la comprensión de la producción del espacio

Juliana Luquez

\section{(2) OpenEdition}

Journals

\section{Edição electrónica}

URL: http://journals.openedition.org/espacoeconomia/2396

DOI: 10.4000/espacoeconomia.2396

ISSN: 2317-7837

\section{Editora}

Núcleo de Pesquisa Espaço \& Economia

\section{Refêrencia eletrónica}

Juliana Luquez, « "Usos e (ab)usos" do conceito de reestruturação: adjetivações e sentidos na compreensão da produção do espaço », Espaço e Economia [Online], 9 | 2016, posto online no dia 19 janeiro 2017, consultado o 24 março 2020. URL : http://journals.openedition.org/espacoeconomia/ 2396 ; DOI : https://doi.org/10.4000/espacoeconomia.2396

Este documento foi criado de forma automática no dia 24 março 2020.

(c) NUPEE 


\section{Usos do conceito de reestruturação}

\section{"Usos e (ab)usos" do conceito de reestruturação: adjetivações e sentidos na compreensão da produção do espaço}

"Uses et abuses » du concept de restructuration: qualifications et significations de la production de l'espace

"Uses and abuses" of the concept of restructuring: adjectival uses are felt in the understanding of the production of the space

Usos e abusos del concepto de reestructuración: adjetivaciones y sentidos en la comprensión de la producción del espacio

\section{Juliana Luquez}

\section{Introdução}

É comum que o conceito de reestruturação acompanhado de diferentes adjetivações (urbana, produtiva, urbano-industrial, imobiliária, metropolitana, etc) seja empregado (ou compreendido), grosso modo, como "novos usos" ou "refuncionalização". Ao discutir esse conceito à luz da noção de produção do espaço ampliam-se as perspectivas conceituais sobre a realidade contemporânea. Essa realidade, cada vez mais urbanizada, torna-se metropolitana; cada vez mais espacialmente complexa e conceitualmente obscura em termos explicativos. Pois já não mais os mesmos conceitos dão conta de representar os diversos processos. Muitas vezes, e a partir de agora cada vez mais, temse feito necessária uma tentativa de explicação do real simultaneamente a uma revisão do arcabouço teórico que herdamos, especialmente, entre anos 1970 e 1990 sobre os temas cidade e urbano, urbanização e industrialização, produção e reprodução do capital, metrópole e metropolização. 
2 Nossa trilha de investigação buscou, primeiramente e com caráter introdutório, 1) perceber a contribuição do conceito de reestruturação para a compreensão da produção do espaço, tendendo à perspectiva com a qual estamos desenvolvendo nossa pesquisa de doutorado em andamento junto ao Programa de Pós-Graduação em Geografia Humana da Universidade de São Paulo (USP) ${ }^{1}$. Em seguida, 2) realizamos um breve levantamento das adjetivações dadas ao conceito de reestruturação e a contribuição desse léxico conceitual para a compreensão das dinâmicas espaciais. Ao final, 3) selecionamos quatro artigos deste levantamento bibliográfico a partir dos quais chegamos a uma questão de método: os usos e o sentido do conceito de reestruturação e a perspectiva metodológica da análise dizem muito sobre as respectivas adjetivações empregadas ao conceito.

Os dois primeiros passos estão considerados na primeira parte da monografia; ficando a segunda parte destinada à discussão estabelecida com as bibliografias selecionadas.

Este trabalho possibilitará uma discussão acerca do conceito de reestruturação na fase atual da acumulação do capital (o que abarca e o que não abarca como potencial explicativo) e contribuirá para uma reflexão dos meandros desse processo na produção do espaço da metrópole contemporânea. Tal aprofundamento teórico contribuirá para uma visão mais ampla das complexidades metropolitanas contidas no objeto da tese de doutorado.

\title{
Reestruturação: compreensão da produção do espaço e usos do conceito
}

\author{
“Toda a formação urbana conheceu uma \\ ascensão, um apogeu, um declínio. Seus \\ fragmentos e restos serviram em seguida para/ \\ em outras formações".
}

5 Essa epígrafe é um trecho do livro 0 Direito a Cidade, no qual Henri Lefebvre continua: "a Cidade passou por períodos críticos. Desestruturações e reestruturações se sucederam no tempo e no espaço [...]". ${ }^{2}$

6 Ao considerarmos a perspectiva de Lefebvre, de movimento e de totalidade, e a reestruturação como um processo assumimos a possibilidade de periodização dos seus diferentes momentos a partir da definição de fases onde podem ser reunidas as características e conhecida a dinâmica específica dos elementos que variam e mudam a composição do espaço ao longo do tempo.

7 A definição de fases é também um meio de reconstituição do espaço em busca de compreendê-lo em sua totalidade, da gênese à evolução, refletindo já sobre suas tendências, que se encontram e se superam por processos que se materializam através das formas e das funções, por meio de estruturas. Neste sentido, pensar as articulações entre os níveis da realidade urbana se coloca como um desafio na análise da produção do espaço, seja no plano teórico-conceitual, seja na compreensão de sua realidade concreta e complexa.

8 Neste exercício analítico é necessário considerar uma regra proposta por Lefebvre: evitar a confusão da continuidade ilusória tanto quanto as separações ou descontinuidades absolutas afim de permitir que o estudo das articulações entre os níveis da realidade possa "pôr em evidência as distorções e defasagens entre esses 
níveis, e não dissolvê-las" ${ }^{\prime 3}$. Em outras palavras, as distorções e defasagens entre os níveis da realidade estudada não devem comprometer a complexidade do todo e sim apontar, com responsabilidade crítica, os diferentes contextos da realidade e não desassociá-los do processo, considerando que é pelo processo que se dá a dinâmica contraditória dos elementos espaciais.

9 Por meio da combinação das categorias analíticas, tais como, forma-função-estrutura, utilizadas como instrumento metodológico, cremos ser possível uma análise do realidade considerando as "estabilidades provisórias e os equilíbrios momentâneos" 4 através dos quais se revela o conteúdo espacial. Para Lefebvre, a forma urbana congrega um movimento de explosão e implosão, ou seja, a partir da implosão a "vida urbana concentra e se acentua no que resta da antiga morfologia (cidades e bairros)"; e a partir da explosão a vida urbana "tende a existir como forma nova que espera por uma base morfológica; [...] provocando o questionamento das formas existentes e do modo de existência (social e metal) das formas"5. As formas se materializam pelas relações concretas entre os indivíduos e por isso se expressam na historicidade das relações sociais, atreladas ao conteúdo da vida urbana que determina suas funções dentro de uma estrutura organizada social e espacialmente. A tríade forma-função-estrutura revela a dinâmica da produção do espaço, espaço que responde às alterações da sociedade a medida que ele, o espaço, também à altera, resultando na transformação dos lugares e de seus elementos.

10 Assim, as transformações socioespaciais se tornam, para nós, a problemática da produção do espaço através da construção de um diálogo com os conceitos de reestruturação socioespacial, ruptura e continuidade. Quando a reestruturação (enquanto processo) se inicia há uma descontinuidade no movimento dos processos engendrados provocando uma ruptura, resultando em mudanças e que, segundo Soja 6: "[..] evoca pois, uma combinação sequencial de desmoronamentos e reconstruções, de desconstruções e tentativas de reconstruções". Os desmoronamentos, as reconstruções, as desconstruções e as tentativas de reconstruções nos sugerem um processo em curso que altera ou insere formas, modifica ou requalifica funções e implica nas relações socioespaciais por meio da estrutura de organização.

11 As transformações socioespaciais tendem a ativar outros processos, acelerar ou romper com movimentos antigos. Contudo, as descontinuidades, provenientes de fases de rupturas entre um momento e outro, não varrem da paisagem urbana seus elementos constitutivos. Ao contrário, as continuidades testemunham o movimento dos processos socioespaciais, estando estas também inseridas no processo de produção do espaço através da conformação da paisagem urbana e aproximam-nos cada vez mais da compreensão da totalidade espacial, quando não encobertas pela análise das transformações recentes como se essas tais não tivessem uma herança histórica nas contradições do processo de produção do espaço.

12 Assim através da eleição do conceito de reestruturação socioespacial, que em nossa perspectiva metodológica, implica nas noções de continuidade e ruptura, temos, respectivamente uma preocupação analítica: as transformações socioespaciais; a paisagem urbana como reveladora de absorções e superações dos elementos espaciais na sua relação com a realidade da sociedade urbana contemporânea; e as diferentes fases que caracterizam os momentos de mudança, qualitativa e quantitativa, do processo de produção do espaço metropolitano. 
13 A evolução urbana da cidade capitalista assume uma estrutura passível de processos dinâmicos e simultâneos, como o de reestruturação socioespacial. A conformação da aglomeração urbana que se estende desde a metrópole até os seus subúrbios amplia a análise desses processos, permitindo considerá-los na reconstrução da realidade urbana e metropolitana. Admitindo que o subúrbio é, tanto quanto a cidade, lugar de contradição e reestruturação socioespacial, lugar de produção e reprodução dos interesses das classes dominantes, lugar de formas e conteúdos que relacionam-se à dinâmica da vida urbana e à impõe um cotidiano; e o quanto o subúrbio metropolitano se relaciona com a própria metrópole, com seus elementos estruturantes e agentes sociais; a investigação das complexidades metropolitanas precisa considerar o arranjo espacial de sua expansão e atentar-se para a relação existente entre essas espacialidades e as formas, funções e estruturas que constituem o emaranhado das desestruturações e reestruturações da metrópole e de sua área de expansão.

14 Nossa abordagem tem se dado a partir da discussão do conceito de reestruturação inaugurado sob a lógica capitalista de produção do espaço da metrópole e de sua região. O conceito de reestruturação nos parece pertinente na investigação das transformações socioespaciais devido ao fato de ele em si se referir a um movimento em curso do processo de produção do espaço, a saber o movimento de estruturação-(des)estruturação(re)estruturação. Este conceito também possibilita um diálogo com os conceitos de ruptura e continuidade, tomados aqui sob uma perspectiva histórica na análise socioespacial, através da qual o processo de produção do espaço aponta contradições e simultaneidades com outros processos espaciais que merecem ser considerados ao longo da pesquisa, sob pena de dissolvermos a realidade complexa das interações socioespaciais.

15 Esses processos produzem resultados a partir de elementos combinados. E o entendimento do conceito de reestruturação, como processo, permite-nos a conexão desses elementos. Considerando a continuidade como a "persistência das características inerentes a um determinado contexto" - conforme uma das acepções do Dicionário Houaiss ${ }^{7}$ - não há como descartar o movimento histórico do processo de produção do espaço a partir do movimento de estruturação-(des)estruturação-(re)estruturação. Tão pouco descartar as fases de ruptura nos seus diferentes momentos.

16 Nesse sentido o conceito de reestruturação possibilita o entendimento das transformações produzidas pelas dinâmicas dos processos socioespaciais contribuindo para a observação do momento em que o que está posto e funcionando, se desmonta e passa a funcionar de outra maneira ou não mais funcionar como antes, mesmo que preserve antigas formas e não anule antigas funções. É essa a dinâmica da produção do espaço urbano no contexto da estrutura capitalista. Para Soja (1993), a reestruturação se inicia quando há uma descontinuidade nos processos engendrados provando uma "freada", resultando em mudanças:

A reestruturação, em seu sentido mais amplo, transmite a noção de uma "freada", senão de uma ruptura nas tendências seculares, e de uma mudança em direção a uma ordem e uma configuração significativamente diferentes da vida social, econômica e política. Evoca pois, uma combinação sequencial de desmoronamentos e reconstruções, de desconstruções e tentativas de reconstrução, provenientes de algumas deficiências ou perturbações nos sistemas de pensamento e ação aceitos ${ }^{8}$.

17 A escolha do conjunto de palavras que Soja utiliza na sua definição de reestruturação, parece-nos adequada diante do que este processo pode abarcar. Especialmente o uso do termo ruptura, que instiga-nos a um aprofundamento. No Dicionário Houaiss ${ }^{9}$ dentre as 
acepções da palavra ruptura emprega-se a definição "interrupção de continuidade" e esta é mui coerente quando utilizada na definição do conceito de reestruturação. A quebra ou a interrupção do contínuo permite-nos uma análise das contradições dos processos socioespaciais inerentes à produção do espaço. A identificação das rupturas sugere o início de uma nova fase, nova não no sentido da heterogeneização da forma, da função e muito menos do conteúdo que a estrutura conserva, mas nova no sentido da superação e também da durabilidade das dinâmicas de homogeneização da estrutura.

Diante das muitas adjetivações que temos encontrado em nossa revisão bibliográfica a respeito do conceito de reestruturação percebemos que a complexidade das dinâmicas espaciais inaugurou um léxico conceitual para analisar e compreender o espaço na sua contemporaneidade. Começamos por listar, a partir do breve levantamento bibliográfico, as adjetivações dadas ao conceito de reestruturação e a contribuição desse léxico conceitual para a compreensão das dinâmicas espaciais.

O quadro (Quadro 1) a seguir destaca algumas das adjetivações mais comuns que o conceito de reestruturação recebe: urbana, urbano-industrial, urbana e regional, da cidade, produtiva, do espaço, imobiliária e metropolitana.

A inspiração para esse artigo no campo do uso e sentidos sobre o conceito reestruturação veio como consequência da leitura do livro "Usos e Sentidos do Termo Estrutura", organizado por Roger Bastide, em 1971. Este livro reuniu diversos pesquisadores, com perspectivas e abordagem teórico-metodológicas diferentes, para debater o conceito de estrutura nas ciências humanas e sociais. 0 texto de Lencioni (1998), intitulado "Reestruturação: uma noção fundamental para o estudo das transformações $e$ dinâmicas metropolitanas" também nos proporcionou uma reflexão ampla da importância do conceito de reestruturação para a compreensão das dinâmicas socioespaciais, atentando-nos para os momentos e o movimento da realização da história produzida a partir de contradições, tensões e descompassos. 
Quadro 1 : Usos e adjetivações do conceito de reestruturação

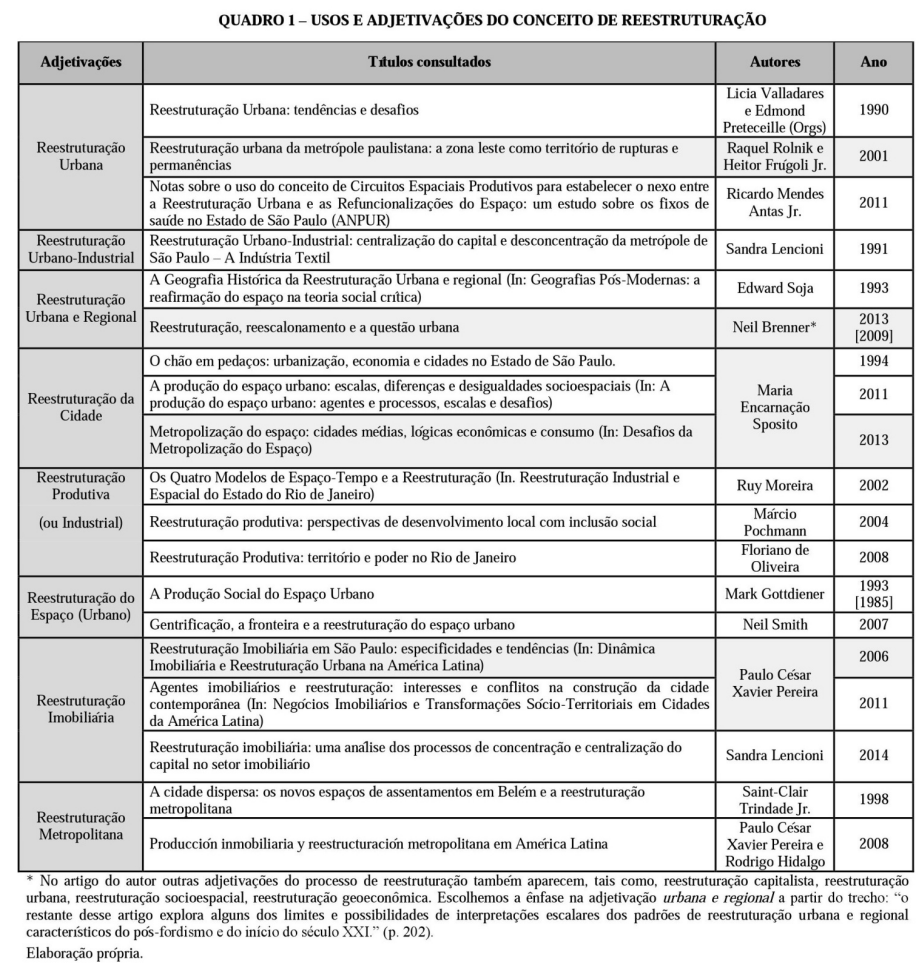

Fonte: Elaboração própria

Diante da variedade de usos do conceito de reestruturação e das diversas adjetivações conferidas a este, aproximamo-nos da advertência feita por Lencioni, no texto acima mencionado, sobre a importância de se voltar a tríade analítica forma-funçãoestrutura.

22 Aqui começamos a nos deparar com possibilidades importantes, no nível do método para compreender as várias adjetivações conferidas ao conceito de reestruturação e seus sentidos na compreensão do espaço.

\section{Reestruturação: adjetivações, sentidos e perspectivas metodológicas}

23 Nesta seção apresentamos quatro artigos do levantamento bibliográfico realizado a partir dos quais chegamos a uma questão de método: o uso do conceito de reestruturação, as respectivas adjetivações empregadas ao conceito e os sentidos dados aos termos nos despertaram para as perspectivas metodológicas utilizadas para pensar a realidade e suas abstrações. Em outras palavras, a construção ou eleição de um conceito e das suas variações adjetivas não são escolhas simples ou isentas de caráter metodológico, justamente por ser um exercício do pensamento sobre o real e porque o conceito não pode conter toda a riqueza do real; mas pode refletir aspectos essenciais de fenômenos ou processos analisados ${ }^{10}$.

Sabemos, pois, que o exercício de pensar o real e capturar conceitualmente o que lhe é essencial combina elementos teóricos e perspectivas metodológicas. Nos textos de Rolnik e Frúgolli (2001), Brenner ([2009] 2013), Sposito (2013) e Pereira (2005) buscamos 
identificar qual a contribuição no uso do termo reestruturação e a partir da adjetivação conferida considerar os aspectos metodológicos contidos no pensamento dos autores para a combinação entre o conceito e sua adjetivação ideal na tentativa de explicar a realidade sob as lentes do método com as quais se investiga.

No texto Reestruturação urbana da metrópole paulistana: a Zona Leste como território de rupturas e permanências, Rolnik e Frúgolli (2001) utilizam o conceito de reestruturação urbana com o entendimento de que este refere-se à dinâmica territorial do modelo centro/periferia, considerando a instalação de shopping centers como elemento dinamizador da lógica espacial, "viabilizando novas formas de organização da produção imobiliária residencial"11.

Deve-se ressalvar entretanto que a multiplicação de shopping centers em si não está necessariamente ligada à reestruturação urbana. Mas dentro do desafio de pensar a articulação desses estabelecimentos com esse processo - ligado a fenômenos como a desindustrialização, o novo papel do setor de serviços e de intervenção urbana do grande capital, os novos padrões de localização da moradia, entre outros - , não significa assumi-los apenas como espaços constitutivos de enclaves excludentes, mas também como espaços que vêm incorporando de forma massificada as classes médias e sobretudo as populares (tanto na estrutura de consumo como na de lazer e entretenimento), incluindo sua inserção nos territórios das periferias consolidadas. 12

26 Os autores consideraram em sua análise a lógica dualista do modelo centro/periferia, concluindo para a metrópole paulistana o que é típico de muitas (ou quase todas) as aglomerações urbanas dos espaços periféricos do capitalismo (as cidades latinoamericanas, asiáticas e africanas): cidades superpopulosas, segregadas social e espacialmente, com largas periferias empobrecidas e em constante expansão, baixa infraestrutura de serviços públicos ou de acesso a atividades especializadas e ao consumo etc.

Os autores consideraram que o modelo centro/periferia "continua marcando, de certa forma, as principais tendências de organização territorial metropolitana, ainda que diversos fenômenos possam estar gradativamente a relativizá-lo, como a diminuição perversa da segregação social" (p. 56). A diminuição perversa da segregação social a qual os autores se referem parece estar ligada à produção doméstica extensiva das residências na metrópole, a produção imobiliária intensiva e a contínua formação de favelas e cortiços no centro e na periferia, espacialmente mesclados dando ritmo a dinâmica de reestruturação urbana considerada, na perspectiva interpretativa do modelo centro/periferia, como uma das tendências da organização territorial metropolitana.

Neil Brenner (2013) explora em seu texto, intitulado Reestruturação, reescalonamento e a questão urbana, os limites e as possibilidades escalares dos padrões de reestruturação urbana e regional. A perspectiva proposta pelo autor é apresentada a partir do que ele chama de problemática da reestruturação $0^{13}$. Brenner evoca questões à essa problemática considerando a importância de "decifrar as paisagens ininterruptamente cambiantes do capitalismo" ${ }^{14}$. O sentido do conceito de reestruturação utilizado pelo autor parece se aproximar da noção de rupturas e transformações do capitalismo na fase contemporânea de sua reprodução. $O$ caminho encontrado por Brenner para essa análise vai ao encontro de "dimensão escalar dos processos de reestruturação sob o capitalismo histórico e contemporâneo"15 , ao que ele chama de reescalonamento. 

vias de método: "as considerações escalares agora figuram explicitamente nas explicações mais espacialmente sensíveis e metodologicamente reflexivas da reestruturação capitalista contemporânea"16. O autor destaca também que a compreensão da produção do espaço e dos processos inerentes à essa produção requer um olhar interessado no aspecto escalar, sendo este também um produto com inúmeras possibilidades de transformação histórica ${ }^{17}$.

30 A questão urbana à qual Brenner se refere vai além de especificidades funcionais da cidade e do urbano, analisados muitas vezes como "sítios geográficos". O autor considera a especificidade escalar, sendo esta "uma materialização geográfica multifacetada das relações sociais capitalistas" ${ }^{18}$.

31 Em suma, Brenner lança mão do conceito de reestruturação considerando a dimensão multiescalar do processo e os arranjos espaciais (e também institucionais) interescalares relação através da qual seria possível, adotando o caminho metodológico da análise escalar dos processos socioespaciais, compreender a produção do espaço e a natureza dos processos inerentes à questão urbana. Brenner, nos sugere que a adjetivação do conceito de reestruturação é uma questão multiescalar sob a lógica de produção capitalista (do espaço, de relações e de coisas), e esta é uma questão de método de análise: "estabelecer uma concepção de escala [...] profícua para decifrar os padrões de reestruturação urbana e regional" 19 .

32 A perspectiva de Brenner parece vir de encontro com a perspectiva de Sposito (2013), nos referimos estritamente ao texto Metropolização do espaço: cidades médias, lógicas econômicas e consumo, o qual discorreremos em paralelo com Neil Brenner. A começar pelo fato de que parece-nos que Sposito (2013) privilegia a especificidade funcional na escala da cidade e não a especificidade escalar ${ }^{20}$ dos arranjos espaciais do urbano e da cidade, essa última considerada por Brenner como parte da dinâmica de produção do espaço.

Sposito adota a noção de sistema urbano para introduzir o debate sobre a formação das redes urbanas brasileiras "cuja a gênese estava associada a diferentes economias regionais" e que a consolidação desse sistema urbano se dá concomitante a industrialização completa no Brasil ${ }^{21}$. Sposito, após um breve panorama da constituição do sistema urbano brasileiro e as redes urbanas a ele associados, apresenta dois movimentos para se compreender a restruturação urbana no Brasil: as novas relações na escala internacional e o papel do consumo. $O$ primeiro movimento está relacionado ao conceito de reestruturação e sua adjetivação "produtiva", ou seja, refere-se à transição do regime de acumulação fordista para o regime de acumulação flexível (p. 133). Para Sposito esse movimento trouxe alterações que "interferiram diretamente da divisão interurbana do trabalho [...] o que teve rebatimentos importantes na economia, na sociedade e no espaço" ${ }^{22}$. A autora ainda acrescenta que:

Esse movimento propiciou desconcentração territorial da atividade produtiva e, em alguma escala, perda relativa dos papéis produtivos das metrópoles, tendo como par combinado a concentração econômica e a centralização espacial ${ }^{23}$.

O segundo movimento ao qual a autora dá destaque é "a redefinição dos papeis urbanos orientados pela mudança no perfil do consumo no Brasil atual, com destaque mais direto às cidades médias" ${ }^{24}$. Esse segundo movimento tem, para a autora, três características específicas: 1) o desenvolvimento e a expansão das novas tecnologias de informação (TCIs), transformando a "competitividade espacial como um elemento novo 
da urbanização", redefinindo as escalas geográficas da rede urbana; 2) em função da diversificação e da complexificação da produção agropecuária, no contexto do agronegócio, as desvantagens para as cidades pequenas e a ampliação da importância e dinâmica das cidades médias e grandes; 3) o desenvolvimento do ensino superior e da pesquisa com a criação e ampliação de Universidades e Centros de Pesquisa em cidades pequenas e médias.

[...] posso afirmar que estas dinâmicas reforçam a tendência de ampliação da dispersão urbana, na escala das cidades, da urbanização difusa, na escala de algumas centenas de quilômetros, tanto quanto processos de aglomeração espacial. De outro lado, todas estas dinâmicas têm rebatimentos na escala regional e nacional, promovendo a passagem de estruturas espaciais mais complexas, muitas vezes policêntricas, que não anulam as anteriores, mas a elas se articulam, gerando interações espaciais de vários tipos, intensidades e direções. ${ }^{25}$

A escala de Sposito, parece-nos, considerando esse texto, ser estritamente geográfica e circunscrita cartograficamente: o local, o regional, o metropolitano, a cidade pequena, média e a metrópole. E não processual e socialmente produzida como sugere Brenner com as noções de escalonamento e reescalonamento associadas ao conceito de reestruturação como potencial interpretativo das complexidades contemporâneas de transformação sob o capitalismo moderno.

Portanto, a autora sugere um par adjetivo ao conceito de reestruturação: reestruturação urbana e da cidade. Sposito justifica "esta duplicação conceitual [...] como um caminho de método" ${ }^{26}$. Essa abordagem metodológica, tem para a autora, três perspectivas, a saber ${ }^{27}$ :

“[A] reestruturação urbana tem relação direta com urbanização e precisa ser compreendida a partir do conjunto de cidades e das relações entre elas, sem o que não se evidencia a redefinição da divisão interurbana do trabalho. A reestruturação da cidade é apreendida mais pelas relações entre as partes da cidade, e pode ser aplicada esta noção toda vez que ocorrem transformações profundas na lógica que orienta a organização dos usos de solo e as articulações entre eles". ${ }^{28}$;

"[0] reconhecimento da reestruturação urbana como articulação entre escalas geográficas, do regional ao internacional, enquanto, de outro lado, a reestruturação das cidades é afeita, não exclusivamente, mas prevalentemente, às lógicas locacionais atinentes à escala local [...]"29;

39 "Considero que a reestruturação urbana revela e é orientada muito mais por processos econômicos e políticos e, na reestruturação das cidades, a dimensão espacial se sobressai com todos os ingredientes afeitos à vida social. A relação entre processos e formas é indissociável neste par, embora considere que, no plano da reestruturação urbana, se revelam os processos como evidência. No que concerne à reestruturação da cidade, os processos de mudança que justificam o reconhecimento de uma mudança profunda, que o termo reestruturação exige, podem se expressar de modo mais claro em formas espaciais" ${ }^{30}$.

Sposito considera a cidade e suas especificidades funcionais intraurbanas e não a relação dos processos socioespaciais e a constituição de arranjos territoriais indissociáveis da noção de escala em uma perspectiva de totalidade analítica do real. A ruptura analítica parece comprometer a noção de totalidade dos processos socioespaciais; contudo se justifica pela escolha metodológica que constrói uma maneira de se pensar o real. 
arto e último texto selecionado para esta exposição, tem como título Reestruturação Imobiliária em São Paulo: especificidades e tendências, escrito por Paulo César Pereira, em 2005. Trata-se de uma contribuição que busca questionar a interpretação do modelo centro/periferia para a compreensão do espaço metropolitano paulistano e "afirmar o entendimento do urbano como totalidade e discutir o chamado padrão periférico de crescimento urbano" ${ }^{31}$. O sentido do conceito de reestruturação, tomado pelo autor, sugere uma perspectiva de totalidade contraditória e aberta, e a adjetivação proposta, reestruturação imobiliária, articula-se entre a globalização e a metropolização. o local e global, o espacial e o social, dando conta simultaneamente do que seria o mais específico e o mais abrangente que afeta a produção do espaço e a distribuição territorial dos grupos sociais. [...] A noção de reestruturação imobiliária unifica diferentes dimensões e níveis de análise referindo-se, também, ao local e ao global enquanto processo e não apenas enquanto escala. Trata-se, portanto, de construir uma noção mediadora da urbanização e da industrialização, que devido aos seus entrelaçamentos já foram considerados processos duplos. Mas, além de pretender dar conta dos laços que unificam estes processos na indústria imobiliária, também, atualiza e identifica o conteúdo do momento em que esses processos ainda separados se imbricam com os da globalização e da metropolização. De forma que na noção proposta estão contemplados as dimensões - social e espacial - e os níveis - global e local. ${ }^{32}$ conceito de reestruturação, qual seja: busca-se explicitar o caráter predominante ou determinante do processo de reestruturação em curso na realidade a qual se quer revelar? Em outras palavras, considerar o que é predominante, no tempo e no espaço, muitas vezes só nos aproxima das características da dinâmica de um processo socioespacial; mas não da sua gênese e da sua historicidade, par indispensável para penetrar as determinações históricas das relações sociais de produção no contexto da atual fase de reprodução do capitalismo.

A adjetivação conferida ao conceito de reestruturação, ora, nos pareceu buscar revelar dinâmicas territoriais intra e interurbanas, ora a compreensão das transformações socioespaciais como momentos do movimento da totalidade. Porém, a percepção da perspectiva metodológica de análise e interpretação do real nos retira de uma confusão teórica acerca do uso e do sentido do termo. Na perspectiva metodológica de Pereira:

$\mathrm{Na}$ reestruturação recupera-se o movimento dos processos sociais e, por isso, se evidencia que os fragmentos emergentes fazem parte de uma estruturação do espaço que não poderá ser compreendido isoladamente, mas como partes de uma estrutura nova, que contém predicados e qualidades sociais que não podem ser coisificados e vão além do de seus artefatos isolados na sua relação com a nova totalidade [...]. ${ }^{33}$

Ao analisar a apropriação do espaço e a expansão metropolitana de São Paulo, Pereira (2006) questiona, como já mencionamos anteriormente, o potencial explicativo do modelo centro/periferia para as transformações contemporâneas da metrópole e de sua 
região e lança mão de uma via metodológica que extrapola as questões geométricas ou de tamanho das cidades e de sua população. Uma via que introduz ao tema as diferentes formas de produção do espaço.

Pereira alerta-nos que o sentido do uso do termo reestruturação imobiliária "encontra especificidade num particular movimento de valorização do capital e da propriedade imobiliária, que tende a funcionar e a existir como capital", o autor considera essa a novidade essencial da reestruturação ${ }^{34}$.

Finalmente, Pereira incide-nos em uma última questão: a relação das reestruturações capitalistas com as formas de produção do espaço. $\mathrm{Na}$ atual fase de desenvolvimento de nossa pesquisa temos visto sentido, inspirados na perspectiva metodológica de Pereira, compreender o processo de reestruturação socioespacial como álibi ${ }^{35}$ do capital na produção (e reprodução) do espaço no contexto metropolitano.

49 Encerramos nosso diálogo teórico, conduzido pelos autores aqui apresentados (Rolnik e Frúgolli; Brenner, Sposito e Pereira), certos de que não se resumem a estes as abordagens do tema tratado, mas que a partir de suas perspectivas metodológicas podemos verificar a abrangência dos usos e sentidos do conceito de restruturação e das adjetivações a ele conferidas.

\section{Considerações Finais}

50 A cidade é uma obra civilizatória da humanidade, não foi o capitalismo que a criou. Ele a tomou. E como modo de produção, ele a produz e se reproduz nela. Fazendo sobressair suas contradições, sem que as possamos superar. A discussão aqui realizada considerou, especialmente, o caráter dinâmico da produção e reprodução do capitalismo na "problemática do espaço".

51 Nossa reflexão sobre os usos, sentidos e adjetivações do conceito de reestruturação não está restrita ao campo metodológico, como privilegiamos debater nesse artigo, mas busca compreender o processo de reestruturação socioespacial, suas rupturas e continuidades relacionando-o ao movimento e aos momentos da produção do espaço metropolitano. Dessa maneira, e conforme destacamos na primeira seção, a eleição das categorias forma-função-estrutura, como instrumento metodológico para a caracterização e análise das fases do processo de reestruturação socioespacial, vem permitindo-nos decodificar os elementos e os agentes da produção do espaço metropolitano ${ }^{36}$, compreender a sua conformação e refletir sobre suas tendências.

\section{BIBLIOGRAFIA}

ANTAS JUNIOR, Ricardo Mendes. Notas sobre o uso do conceito de circuitos espaciais produtivos para estabelecer o nexo entre a reestruturação urbana e as refuncionalizações do espaço: um estudo sobre os fixos de saúde no Estado de São Paulo. In: Anais do XIV Encontro da ANPUR, Rio de Janeiro, 2011. 
ARRIGHI, Giovanni. O Longo Século XX: dinheiro, poder e as origens de nosso tempo. São Paulo: Contraponto Unesp, 1996.

BASTIDE, Roger (Orgs.). Usos e Sentidos do Termo Estrutura. São Paulo: Editora da Universidade de São Paulo/Editora Herder, 1971.

BRENNER, Neil. Reestruturação, reescalonamento e a questão urbana. Revista GEOUSP - espaço e tempo, São Paulo, n. 33, pp. 198-220, 2013.

CAMARGO, Cândido Procópio Ferreira et al. São Paulo: crescimento e pobreza. $4^{a}$ Ed. São Paulo: Edições Loyola, 1975.

GOTTDIENER, Mark. A Produção Social do Espaço Urbano. São Paulo: Editora da Universidade de São Paulo, 1993.

LEFEBVRE, Henri. A cidade do capital. Rio de Janeiro: DP\&A, 1999.

LEFEBVRE, Henri. A Revolução Urbana. Belo Horizonte: UFMG, 2008.

LEFEBVRE, Henri. O Marxismo. Porto Alegre: L\&PM, [1971] 2013. Coleção L\&PM POCKET, v. 784.

LEFEBVRE, Henri. Sociologia de Marx. 2. ed. Tradução de Carlos Roberto Alves Dias. Rio de Janeiro: Forense Universitária, [1966] 1979.

LEFEBVRE, Henri. Forma, função, estrutura em O Capital. In: LEFEBVRE, Henri. L'Idéologie Structuraliste. Paris: Éditions Anthropos, 1971. (Tradução livre)

LEFEBVRE, Henri. A vida cotidiana no mundo moderno. São Paulo: Editora Ática, 1991.

LEFEBVRE, Henri. La production de l'espace. 4e éd. Paris: Éditions Anthropos, 2000.

LENCIONI, Sandra. Reestruturação: uma noção fundamental para o estudo das transformações e dinâmicas metropolitanas. In: Anais do VI Encontro de Geógrafos da América Latina, Buenos Aires, 1998, CD-ROM.

LENCIONI, Sandra. Observações sobre o conceito de cidade e urbano. São Paulo: Revista GEOUSP - Espaço e Tempo (USP), v. 24, p. 109-123, 2008.

LENCIONI, Sandra. Reestruturação urbano-industrial no estado de São Paulo: a região da metrópole desconcentrada. In: Espaço \& Debates. São Paulo: NERU, n.38, 1994, p.54-61.

MARICATO, Ermínia. (Org). A produção capitalista da casa (e da cidade) no Brasil industrial. São Paulo: Alfa e Ômega, 1979.

MEYER, Regina Maria Prosperi et al. São Paulo Metrópole. São Paulo: EDUSP/Imprensa Oficial do Estado de São Paulo, 2013.

MOREIRA, Ruy (Org). Reestruturação Industrial e Espacial do Estado do Rio de Janeiro. Rio de Janeiro: UFF, 2002.

OLIVEIRA. Floriano José Godinho de. Reestruturação produtiva e regionalização da economia no território fluminense. Rio de Janeiro: Garamond, 2008.

OLIVEIRA. Floriano José Godinho de. Investimentos públicos e desenvolvimento local: sentidos estratégicos dos recentes projetos e políticas públicas no Rio de Janeiro. Scripta Nova (Barcelona), v. XII, p. $\mathrm{n}^{\circ}$ (84), 2008.

OLIVEIRA. Floriano José Godinho de. Restruturação Econômica, Poder Público e Desenvolvimento Social: Possibilidades de Disputas e de Recomposição do Poder no Território. Scripta Nova (Barcelona), v. XI, p. nº (65), 2007. 
PEREIRA, Paulo César Xavier. Reestruturação Imobiliária em São Paulo (SP): especificidade e tendência. In: Anais do X Encontro de Geógrafos da América Latina, São Paulo, 2005.

PEREIRA, Paulo César Xavier. Pereira, Paulo César Xavier; et al (Org.). Dinâmica imobiliária e reestruturação urbana na América Latina. Santa Cruz do Sul: EDUNISC, 2006.

PEREIRA, Paulo César Xavier. Agentes imobiliários e reestruturação: interesses e conflitos na construção da cidade contemporânea. In: Pereira, Paulo Cesar Xavier (Org.). Negócios imobiliários e transformações sócio-territoriais em cidades da America Latina. São Paulo: FAUUSP, p. 23-31, 2011.

PEREIRA, Paulo César Xavier. Reestruturação imobiliária e produção do espaço metropolitano: nega o urbano e a urbanização tradicional. In: FERREIRA, Alvaro; RUA, João; MATTOS, Regina Célia. (Orgs). Desafios da Metropolização do Espaço. Rio de Janeiro: Consequência, 2015.

POCHMANN, Márcio. Reestruturação produtiva: perspectivas de desenvolvimento local com inclusão social. São Paulo: Editora Vozes, 2004.

ROLNIK, Raquel; FRÚGOLI, Heitor. Reestruturação Urbana da Metrópole Paulista: a Zona Leste como território de rupturas e permanências. In: Cadernos Metrópole, v. 6, São Paulo: 2001.

ROLNIK, Raquel; SOMEKH, Nadia. e KOWARICK, Lúcio. (orgs.) (1990). São Paulo: crise e mudança. São Paulo, Brasiliense

SANTOS, Milton. Espaço e Método. São Paulo: EDUSP, 2014.

SMITH, Neil. Gentrificação, a fronteira e a reestruturação do espaço urbano. Espaço e Tempo, São Paulo, no 21, pp 15-31, 2007.

SOJA, Edward W. Geografias Pós-Modernas. A reafirmação do espaço na teoria social crítica. Rio de Janeiro: Jorge Zahar Editor, 1993.

SPOSITO, Maria Encarnação Beltrão. A produção do espaço urbano: escalas, diferenças e desigualdades socioespaciais. In: CARLOS, Ana Fani Alessandri; SOUZA, Marcelo Lopes; SPOSITO, Maria Encarnação Beltrão. (Orgs). A Produção do Espaço Urbano: agentes e processos, escalas e desafios. São Paulo: Contexto, 2011.

SPOSITO, Maria Encarnação Beltrão. Metropolização do espaço: cidades médias, lógicas econômicas e consumo. In: FERREIRA, Alvaro; RUA, João; MATTOS, Regina Célia. (Orgs). Desafios da Metropolização do Espaço. Rio de Janeiro: Consequência, 2015.

TRINDADE JUNIOR, Saint-Clair. A cidade dispersa: os novos espaços de assentamentos em Belém e a reestruturação metropolitana. São Paulo: FFLCH/USP, 1998. (Tese de doutorado)

VALLADARES, L; PRETECEILLE, E. (Orgs.). Reestruturação urbana: tendências e desafios. São Paulo: Nobel, 1990.

\section{NOTAS DE FIM}

1. Essa pesquisa tem apoio e financiamento da Fundação de Amparo à Pesquisa do Estado de São Paulo - FAPESP.

2. Lefebvre, 2006; p. 55 - grifo nosso.

3. Lefebvre, 2006; p. 52.

4. Lefebvre, 1971; p. 189.

5. LEFEBVRE, 1991; p. 188.

6. Soja,1993; p. 193. 
7. Em CD-ROM, 2009.

8. SOJA, 1993; p. 193 - grifo nosso.

9. Ibidem.

10. LENCIONI, 2008.

11. Rolnik e Frúgolli, 2001: p. 46.

12. ROLNIK; FRÚGOLLI, 2001; p. 55.

13. Neil Brenner, 2013: p. 200.

14. Neil Brenner, 2013:p. 200.

15. Neil Brenner, 2013:p. 201.

16. Neil Brenner, 2013:p. 201.

17. Neil Brenner, 2013: p. 201 e 202.

18. :Neil Brenner, 2013:p. 204.

19. Neil Brenner, 2013::p. 209.

20. Considerando a especificidade escalar como sendo um produto das dinâmicas de transformação socieoespacial sob o processo de reestruturação do capitalismo, e não a localização geográfica de processos e fenômenos analisados.

21. SPOSITO, 2013 :p. 131.

22. SPOSITO, 2013: p. 133.

23. SPOSITO, 2013; p. 134.

24. SPOSITO, 2013: p. 135.

25. SPOSITO, 2013; p. 138.

26. SPOSITO, 2013 p.141.

27. Sposito toma como opção teórica e metodológica "reservar o conceito de restruturação urbana para tratar dos papéis que diferentes cidades desempenham na divisão interurbana do trabalho, enquanto procuro distinguir as mudanças nos espaços urbanos - reestruturação das cidades - que amparam e expressam tais transformações nos papéis" (p. 141).

28. SPOSITO, 2013p. 141.

29. SPOSITO, 2013p. 141.

30. SPOSITO, 2013p. 142.

31. PEREIRA, 2005:p. 2.

32. PEREIRA, 2005; p. 4.

33. PEREIRA, 2006; p. 8.

34. Pereira, 2006 p. 2 e 11.

35. Álibi: constitui um discurso das representações hegemônicas. Negação das contradições. "A natureza fornece um álibi àqueles que querem fugir das contradições ou dissimulá-las. " (LEFEBVRE, 1991; p. 80).

36. Vimos dedicando nossa pesquisa a compreensão da produção do espaço metropolitano fluminense, considerando, especialmente, as especificidades da estruturação e reestruturação socioespacial e da expansão metropolitana a partir da tríade fragmentação-hierarquização-homogeneização do espaço nos subúrbios metropolitanos.

\section{RESUMOS}

Acompanhado de distintas adjetivações, é comum que o conceito de reestruturação seja empregado ou compreendido, grosso modo, como "novos usos" ou "refuncionalização". Com base no levantamento de diferentes autores, chegamos a uma questão de método: discutir a reestruturação à luz da noção de produção do espaço amplia as perspectivas conceituais sobre a realidade contemporânea. 
Accompagné de différentes significations, le concept de restructuration est normalement utilisé soit que "nouveaux uses», soit que "refonctionnalisation». A partir d'une enquête de différentes auteurs, on arrive à une question de méthode : discuter la restructuration à la lumière de la notion de production de l'espace signifie l'ampliation du champ conceptuel pour comprendre la réalité contemporaine.

It is common that the idea of restructuring accompanied by different adjectives is employed (or understood), roughly as "new uses" or "defunctionalisation". Pursuant the space production notion is possible to picture an extended perspective on contemporary reality. From an investigation on different authors, a new issue of method was reached: the use of the concept of restructuring, their adjectives used to the conception and meanings given to terms draw our attention to the methodological perspective used to think about reality and its abstractions.

Es común que el concepto de reestructuración, seguido de diferentes adjetivaciones, sea empleado (o comprehendido) como "nuevos usos" o "re funcionalización". Discutir este concepto a la luz de la noción de producción del espacio hace posible ampliar las perspectivas conceptuales sobre la realidad contemporánea. Desde diferentes autores, llegamos a una cuestión de método: el uso del concepto de reestructuración, las respectivas adjetivaciones adjuntadas al concepto y los sentidos atribuidos a los términos, llamarán nuestra atención para las perspectivas metodológicas utilizadas para pensar la realidad y sus abstracciones.

\section{ÍNDICE}

Palavras-chave: conceito de reestruturação, produção do espaço, teoria, método, capitalismo.

Palabras claves: reestructuración, espacio, método, teoría, capitalismo.

Mots-clés: le concept de restructuration, la production de l'espace, méthode, théorie, capitalisme.

Keywords: concept of restructuring, production of space, theory, method, capitalism.

\section{AUTOR}

\section{JULIANA LUQUEZ}

Doutoranda do Programa de Pós-Graduação em Geografia Humana da USP. E-mail: julianaluquez@usp.br. Apoio e financiamento da Fundação de Amparo à Pesquisa do Estado de São Paulo - FAPESP. 